\title{
Knowledge Management in the UK Water Industry
}

\author{
Andrew Kamunda, Suresh Renukappa and Subashini Suresh \\ Built Environment, Faculty of Science and Engineering, University of Wolverhampton, UK \\ Akamunda@gmail.com \\ S.Subashini@wlv.ac.uk \\ Suresh.Renukappa@wlv.ac.uk
}

\section{Abstract}

The UK government has set ambitious targets for the construction industry to maintain global competitiveness. It aims to remove barriers, increase productivity, improve competition, at the same time benefiting the customers by lowering water bills. Through the water industry regulators, Ofwat, Defra and DWI, the privatised water industry saw competition opened for business and non-household water customers in 2017. Knowledge has become known as the major resource organisations must have to maintain a competitive advantage. Management of this organisational knowledge, commonly referred to as Knowledge Management (KM), creates business value generating competitive advantage, enabling creation, communication and application of various knowledge to achieve business goals. Although the UK water industry is information and knowledge rich, there is limited research in the KM subject within this industry. Therefore, the aim of this study is to explore, examine and understand how knowledge is being managed in the UK water industry. A qualitative case study was used for the collection and analysis of data with the results obtained through review of water company supply chain processes, documents, observations and semi structured interviews. Organisational culture and the need to maintain and retain business competitiveness was the major drive for implementation of KM, as found in this study. The water industry and its supply chain are changing their goals and objectives to align them with KM practices, identifying needed knowledge, creating KM resources, sharing and fostering knowledge through information technology tools. The study concludes that the knowledge rich water industry has put in place measures and processes fundamental to KM and will eventually take the next step for its full implementation. Organisational leadership and management were the initiating and driving positive KM cultures, placing knowledge as the major project resource. The current drive to create, foster and provide resources for KM through organisational culture changes and making use of information technology should continue to be invested in. This will allow organisations to maintain, sustain and increase competitiveness, improve productivity whilst meeting business goals. The advancement of information technology should also be taken advantage of as an enabler for implementing of KM strategies.

Key words

Knowledge management, information technology, organisational, competitiveness

\section{Introduction}

The construction industry is expected to grow by $70 \%$ by the year 2025 . The UK government has committed to building a competitive advantage in smart construction and digital design. (HM Government, 2013). This is coupled by a need to improve productivity, create open and competitive markets which leads to benefits for customers. This implies removing barriers to competition, which inhibit organisations' growth. (HM Treasury, 2015). The UK government through the Construction Strategy 2025 identified that the construction industry is 
also affected by lack of integration, low levels of innovation, lack of knowledge share when a project in completed and high construction costs.

The water industry was public up until 1989 when it became private through the Water Act (Ofwat and Defra, 2006). The water companies are monopoly suppliers to most public consumers, who cannot choose their water supplier (Priestly and Hugh, 2016), responsible for providing services and should maintain the ability of their water and wastewater networks and treatment works so that they can continue to carry out their duties. They should comply with European and national drinking water and environmental regulations implemented by Defra, the Welsh government, the Environment Agency (EA) and the Natural Resources Wales (NRW) (Lobina and Hall, 2001, Ofwat and Defra, 2006 and NAO, 2015). However, competition The Water Act 2014 opened up competition for non-household customers in 2017, which include businesses, charities and the public sector, who can choose and change water suppliers in England. The Water Act 2014 aims to also bring in other players in the water industry market (Ofwat, 2017 and Priestly and Hugh, 2016).

Opening the UK water retail market for competition and other water industry threats, frictions is having a negative impact on customers as identified by Ofwat, (Ofwat, 2018) organisations have to find new solutions to stay ahead of competition (Dave and Koskela, 2009). Knowledge was identified as a major organisational resource with the ability, if used effectively to keep a competitive advantage (Dave and Koskela, 2009). This is supported by Perrott (2007) who states that knowledge is the critical currency in a demanding world. This concept can be seen by how Ofwat selected, through tendering, its 2019 price review delivery partner; selecting an organisation that is able to work collaboratively, whilst supporting Ofwat's learning environment by knowledge sharing and delivering learning amongst Ofwat's staff (Ofwat, 2017).

Past research has identified that the construction industry is considered not to have formal and proactive Knowledge Management (KM) processes, though there exist examples of good practice in activities that make contributions to it (Nevo and Chan, 2007). Robinson, et al, (2005) highlights that organisations need to drive innovation to become competitive through learning and knowledge sharing. The ability of organisations to effectively manage this knowledge has been recognised as a vehicle for organisations to drive business improvement (Kamara, et al, 2002). KM is considered a way in which organisations work with information and data, and in assisting people to share knowledge and collaborate (Malone, 2013).

\section{Knowledge Management: What would it mean for the UK Water Industry}

\subsection{The definition}

According to the Oxford dictionary, knowledge are facts, information and skills acquired through experience or education; being either theoretical or practical.

Knowledge can be either be tacit or explicit. Tacit knowledge is regarded as personal hidden knowledge, not usually captured, but demonstrated through expressible knowledge and actions. Where as explicit knowledge can be written and transmitted in formal languages (Visscher, 2006).

The definition of KM was arguably first provided by Davenport in 1994 as "a process of capturing, distributing and effectively using knowledge." as stated by Koenig in 2018, who argues that there hasn't been a better definition since then. In Tiwana (1999) Davenport and Prusak defined KM as an ever-moving mixture of gained experience, values, information, expert insight and grounded intuition which offers an environment for evaluating and incorporating new experiences and information.

The Association of Project Management (APM) (2012) simplifies the definition of KM as a methodical management of information and learning. Whereas the Oxford Dictionary states that KM is

"efficient handling of information and resources within a commercial organisation". 
The concept of KM is regarded as a dynamic cycle of knowledge related organisational performed activities carried out to meet strategic aims. The activities include (a) acquiring, applying and disseminating of existing and newly created knowledge (b) creating conditions that allow learning and ways of sharing both explicit and tacit knowledge and (c) use of information technology (IT). KM is about ensuring that the right knowledge required to perform tasks is provided at the right time, and be able to use it (GWOPA, 2017).

Lehaney, et al. (2004) highlights that KM is being perceived as being so entwined with technology that its critical aspects and success factors are being lost; document management software, databases etc. are being labelled as KM solutions and gives rise to the "false" myth that KM is IT. Information systems provides the right information to the right person at the right time, but KM goes far beyond that. GWOPA (2017) supports this view and brings acknowledgement that KM becomes more effective when it is simultaneously focused on people, processes and technology i.e. organisational cultures.

KM comprises of a variety of tools and techniques some of which include the (a) training (b) action reviews (c) communities of practice (d) knowledge audits (e) developing KM strategies ( $f$ ) exit interviews (g) identifying and sharing best practice (h) knowledge centres (i) knowledge harvesting (j) peer assists (k) social network analysis and (I) story telling (GWOPA, 2017).

\subsection{Knowledge Management Drivers}

In the water industry, Ofwat and Ofgem (2017) stated that the world we live in is data rich and is becoming increasingly technologically driven. The UK regulators, including Ofwat, are pushing for organisations to harness this data, intelligence and insight to deliver tailored, seamless and excellent customer service. Since opening the retail water market in 2017, Ofwat identified that there are still issues that have been affecting customers which include lack of complete, accurate data, poor performance against industry standards and collaboration which all have raised costs. Ofwat is pushing for improvements in these areas, in data quality and collaborating with the respective organisations to best support effective competition (Ofwat, 2018).

The drivers for KM implementation also stem from organisations realising knowledge drain when senior staff leave without knowledge transfer to junior staff. This is coupled by loss of information as organisations grow, with a need to remove barriers that inhibit knowledge share. KM is also implemented to capitalise on organisational knowledge, increasing accountability, transparency and assisting in business sustainability by knowledge and encouraging innovation. (Odell, 2013).

Odell (2013) goes on further to state that one of the key drivers lies in the definition of KM, which is to foster a deeper understanding within a large group of people in an organisation so that they can share a greater level of tacit knowledge and make better organisational decisions. GWOPA (2017) shares the same understanding highlighting that the quality of the performance, decisions and actions undertaken by staff in specific situations at all levels is dependent on the extent of available knowledge and its application.

\subsection{Knowledge Management Benefits}

Koenig (2018) rightly points out that KM aims to create an environment which has rich, deep, open communication and accessible information across a firm. He points out that we are now all information workers and that KM creates organisational competence to establish exceptional situational awareness that allows making the right decisions. Good KM reduces risks and increases efficiency by reuse of proven approaches and avoidance of known pitfalls. This has the added benefit of encouraging participation when individuals and teams see recognition of their contributions (APM, 2012). Northumbrian Water used a combination of knowledge and technology at a relatively small scale yielding large business impact. A cost saving of $f 8.75$ million and a time saving of three years against traditional methodologies to obtain and process missing information was made. This piece of work was undertaken to test the impact of innovation and technology in meeting Ofwat need to drive efficiency and potential for setting future targets. However, the case study by KPMG was not formal KM, but deemed as innovation of combining employee "knowledge" and use of technology to solve the need to maintain asset data and adding more information into geographical information systems for future use (KPMG, 2018). 
Tiwana (1999) states that KM creates business value, generates a competitive advantage, and it addresses business problems. This can be generating and delivering innovative products/services, managing and developing business relationships, both internal and external, as well as improving work practices and processes. According to the Association of Project Management (APM) (2012) KM turns personal information and experiences into collective knowledge which can be shared throughout an organisation for decision making and to avoid making past mistakes. Hence it supports organisational learning and maturity. This is shared by GWOPA (2017) who highlight that organisational performance lies in its employees and the knowledge they possess, which is now seen as a valuable resource that needs to be managed carefully. They go on further stating that some water companies implementing KM are benefitting from having well prepared staff, improved performance, better working environments, improved customer service and the ability to retain talented staff.

\subsection{Knowledge Management Application and Challenges}

However, Davenport (2015) highlighted that KM "is gasping for breath". It is no longer a term that is regularly used. He cited reasons for the fading as (a) difficulty to change behaviours (b) everything being technology decentral (c) time consuming to search and digest stored knowledge (d) google impact and that (e) data and analytics derived knowledge is never incorporated into KM. This is supported by the APM (2012) who highlighted that knowledge face the challenge of being difficult to collect and encouraging its use, and is seen as an onerous distraction to managers' core roles.

Davenport (1999) highlights that organisations should not fall into the above pitfalls to enable KM to thrive and there shouldn't be an over reliance on technology alone. The APM (2012) recommends that project management must include processes of knowledge capture as work is continuously undertaken and "experience learning" must become a habit to workers, supported by organisational assurance processes.

A study on KM in the water industry was carried out by Water Operator Partnerships (WOP) which identified that successful application of KM is a complex activity which requires multi-disciplinary approach. The findings recommended that water operators should create clear knowledge visions and strategies which are then linked to performance. They should also make efforts to increase readiness to accommodate KM interventions considering some established role of organisational variables in making KM work (GWOPA, 2017).

\section{Research Methodology}

Research must be conducted to correspond with the needed data availability (Naoum, 2007). Hence the aim of the research was to understand KM implementation in the water industry including obtaining perceptions, experiences and effects on the delivery of construction projects. The research aim pointed towards an investigative research approach into the implementation of KM in the UK water industry as this research area is very limited. A need to conduct a research should correspond with the availability of the needed data as pointed out by Naoum (2007). Hence, a qualitative research approach was selected as its primary focus is on the evidence that a researcher can understand people, or organisational behaviours, what is happening and by what people say or do (Gillham, 2000).

Case studies are used to document and analyse implementation processes and outcomes of interventions, (Yin, 2012) hence its selection for this research. A case study approach is comprehensive and incorporates multiple data sources to provide detailed account of complex research phenomena in real life context and is used to support arguments (Morgan, et al, 2017) It is a viable way of carrying out qualitative research strategy and involve in-depth exploration (Creswell, 2009). However, these are not generalised (Naoum, 2007) which is regarded as lack of validity as conclusions are related to an event and an in-depth analysis of a specific issue. The data collection and in-depth analysis were carried out for four water companies, through review of project delivery processes for selected four organisations which form respective supply chain, respective selected 
documents, observations and semi structured interviews of three project participants, one per each water company, except one, based on theoretical sampling technique.

The case study included reviewing the organisations intranets to review tools available for KM implementation and to get an understanding of how data, information and knowledge is managed for projects delivery. In addition, observations were carried out on staff to understand behaviours, attitudes and perceptions on how projects were delivered using respective organisational processes, use and adherence to processes and understand how effective these set systems are. After review of intranet and observations, semi-structured interviews were carried out to confirm initial findings and fill in the gaps on KM implementation. The analysis of the interviews was undertaken using Content Analysis which is practical when semi-structured questions are used in soliciting information, as it allows for defining content categories through coding. Selecting and defining categories (codes) is like treating semi-structured questions as if they were closed-ended in survey research (Naoum, 2007).

\section{Research Findings: KM in the Water Industry}

\subsection{Opportunities for KM application in the Water Industry}

The water companies make strategic decisions for project commencement based on business needs and to meet regulatory targets, i.e. Ofwat, Defra, EA etc. (Ofwat, 2018). Regulatory targets are primarily customer focused, aiming to improve water supply services. The water companies are also carrying out strategic work to enable them to meet the retail market competition opened by Ofwat in 2017 (Ofwat, 2016). This research has identified that this is driving water companies to innovate to allow them to keep their existing retail customer base and compete where opportunities open. The water companies together with their price review delivery partner develop and submit their plans for a five-year expenditure, called an Asset Management Period (AMP) to Ofwat. The outcomes of the price review determinations enable water companies to develop strategies to maintain their assets hence they engage consultancies and contractors to deliver set projects to defined budgets. Due to the vast amount of data, information and knowledge exchange during project delivery, there is a need to effectively manage it, with adoption of KM seen as a key methodology to address this in the text mentioned earlier.

It has been noted by several organisations and researchers that the world is changing and recently the Association of Consultancy and Engineering (ACE, 2019) supported this argument. It is argued that the technological, environmental and human advances have disrupted many industries, the water industry included. The ACE (2019) highlights that a new era, which they welcome, will require the industry to adapt and there is ongoing research to ready the industry for this new way of working. Led by data and technology, new tools are emerging that are allowing project monitoring from desks, with the BIS (2009) stating that we are now living in a digital world.

The research has identified that projects are still delivered using the RIBA plan of work which includes progression from inception, to feasibility, outline and detailed design, to construction, commissioning and handover (RIBA, 2013). This project delivery process led by a Project Manager at each stage, offers opportunities for implementing KM. In the context of the APM (APM, 2012) processes, the project manager is tasked with implementing KM. In this study it was identified that KM was a rarely mentioned subject, however there were tools and activities carried out during project delivery that supported KM practices.

\subsection{Supporting KM Practises}

Lehaney (2004) pointed out that the enormous change the world is going through highlights the importance and need of communication and the greater importance of KM. It works at the interface of people, processes, technology and is about the creativity of humans and exchange of ideas. Within the practices and processes of the research cohort were evidence of $\mathrm{KM}$, though not a formal subject, which included information and knowledge capture and sharing through the project delivery process and supply chain competence. 
Organisational competency to identify and implement good KM practises was a major contribution to retaining the competitive edge (Odell, 2013, GWOPA, 2017 and Visscher, et al, 2006) by the water industry supply chain. One of the water company's delivery partners has started to formally introduce KM in its water division with an in-house presentation carried out on the benefits of KM. The water company was introduced to elements of KM, aligned to its own goals, by the organisation. The water company then adopted the approach by making it a framework wide challenge to adopt it and foster the need to harvest knowledge and share. This approach also meets the call by Defra for a change to stimulate innovation and growth encouraging efficiency and improving customer service (Defra, 2011). An internal water company bulletin was shared highlighting the benefits which included savings in cost and time associated with "knowledge harvest and sharing".

One key change for one of the four organisations was introduction of a prompt within their monthly progress meetings which now included the prompts on "what have we learnt in the past month and have we shared it?" to enable capture of tacit and explicit knowledge. This approach by the leadership team has enabled KM to become a subject that can be talked about and supported within the water industry and is supported by Oliveria, et al (2014) who state that KM mechanisms adoption should be based on the phases of KM implementation; which is in its infancy for the organisations in this research. The project delivery process has started official KM practices, though at a slow pace.

There is a UK target to be at the forefront of digital economies through the call by the UK government's "Digital Britain" initiative. For designers, researchers and engineers in the advanced industries, it has been identified that computer generation and simulations and reliable large-scale file transfers are now crucial trade tools like knowledge-based organisations (BIS, 2009). One interviewee who develops designs and drawings said "Knowledge management for me is Building Information Modelling" which is a new way of how projects are being delivered. This research identified that the UK water companies continue to invest in information technology that enables them to better manage project information. Emerging technology, software and hardware is being procured to meet the everchanging digital world to ensure that the competitive edge is maintained. Project delivery teams are being continuously updated on technology advancement in respective fields to ensure that they continue to make informed, quicker and better decisions. Lehaney et al (2004) and GWOPA (2017) both highlight that use of technology is another practice tool for KM which the water companies are using.

\subsection{Harvesting "Tacit Knowledge"}

It is a held belief that "tacit knowledge" is difficult to manage and harness (GWOPA, 2017 and Koening, 2018) with Odell (2013) arguing that this is between 70 to $90 \%$ for significant information. This research identified that project participants carry with them project knowledge, which, some is never captured in any form. Project performance severely suffered when key personnel left or was reallocated to another workstream. This was the case for an individual who had to spend time trying to understand reasons for decisions made in the past. One of KM's overarching principles is to have the right information to the right person at the right time (GWOPA, 2017), however the research identified some failings in this regard. However, one interviewee highlighted measures in place to capture and share tacit knowledge which included referring to lessons learnt registers at project start and identifying staff / individuals / organisations who were involved in the previous stage and involve them in the early stages of the next to pass on that knowledge. This was identified for one infrastructure project were significant cost and time savings were made when this background "tacit" knowledge was harnessed from a key staff member who had been involved in the previous stage. On the contrary, another project incurred significant costs associated with trying to find historical information and understand historical design decisions made.

The research also identified that the researched organisations have started the equivalent of social media platforms for knowledge share, capture and pulling global expertise. An example of this is a platform called "yammer", which is a Microsoft product. Yammer is a social network which was created for better teamwork for sharing, creating and editing content across an organisation (Microsoft, 2019). On this platform, staff can seek advise and help within an organisation by raising a topic and asking questions. Usually several responses are obtained on a subject matter and references to key experienced staff, technology or organisation is made to ensure that the required information and knowledge is harnessed and shared. This also meets the UK governments pillar of encouraging innovation and helping resources, in this case knowledge and information, to move to their most productive uses (HM Treasury, 2015). 
Two of the organisations in the research area were identified to be identifying and documenting competency levels of staff. The purpose of being to identify knowledgeable or experienced staff who would be called upon when needed for other projects. These "knowledgeable staff" would pass forward their knowledge when needed for supporting junior staff, other projects input and identify key resources for tender submissions. This supports GWOPA (2017), Lehaney et al, (2004), and Visscher et al, (2006) who highlight that knowledge is a resource useful for creating a competitive edge. This has allowed the organisations tender for projects in other UK regions, by harnessing this knowledge to gain a competitive edge.

Tiwana (1999) goes on further to state that knowledge must be stored in a way that it is insightful, relevant and useful. This was the case for the organisations in this research. Information systems were set to be user friendly, easy to use and access even for those without extensive experience on its use. Lessons learnt registers were created and stored on intranet that staff members could update and refer to when needed. In addition, cultures of good / positive interventions in all work space aspects, design, technical and nontechnical etc was developed. Everyone was encouraged to contribute to the lessons being learnt with a monthly target to review, feedback and share the lessons learnt. Incentives were placed on highly ranked lessons learnt with a commendation given. In addition, experienced staff are now tasked with leading short presentations or workshops in which they present on the certain "knowledge" topics; training has been identified as key although one of those interviewed did not believe that enough was being done to meet their training needs. This was attributed to a shortage or unavailability of experienced staff who could pass on the knowledge as well as budgetary constraints.

\subsection{Storing, Sharing and Making "Tacit and Explicit Knowledge" Available}

Information Technology has long been associated with effective KM implementation, however its initiatives should also simultaneously focus on organisational elements which includes cultures, processes (GWOPA, 2017). The organisations studied employed this approach, without defining KM as a process. The findings include existence of different Communities of Practices (CoP) on different subject areas which were deemed to be the "knowledge hubs" on respective subject areas. These CoPs were responsible for defining standards and were the knowledge centres to respond to queries by those lacking the know how in their subjects. This organisational approach enabled availability of respective information and knowledge, though the findings point towards delays in getting responses due to commitments on other projects. However, there existed an organisational initiative to harvest and share engineering knowledge within the water projects, addressing the harder part of KM.

The water companies and their supply chain in this research utilise cloud-based information technology for hosting and sharing vast amounts of data, information and knowledge. Best practice guidance design standard documents, drawings and specifications are made readily available on intranets, with indexes provided to point staff in the right direction. More often, staff found it difficult to find this information and knowledge due to lacking knowledge of where they are stored on the intranets. It was found that new staff are relying on staff that have used these systems before to guide them to where documents and drawings are stored and extracted. KM is about making knowledge available to the right person at the right time (Robinson, et al, 2005). However, shortfalls have been identified within some of the studied organisations because of not making explicit knowledge readily accessible leading the water companies to raise improvement notices as additional unplanned costs were being incurred, programmes prolonged and resultant poor-quality designs lessons are being learnt by all the four organisations studied, even the one that had formally introduced KM.

\section{Conclusion and recommendations}

The opening of the UK retail water market has meant that water companies and its supply chain had to find ways of being competitive to retain their customer base. Knowledge is known to improve competitiveness and organisations have been findings ways of formally and informally implementing KM. These KM benefits together with the need to retain organisational knowledge due to staff changes, movements and need to identify, harvest and share the ability to make informed decisions has led to organisations implementing KM. There have been two isolated situations of KM implementation in the water industry, but these have shown that it has not matured to levels that would allow organisations to fully benefit from it. Within the UK, the water industry does not formally implement KM, but rather use cloud based, collaborative tools to share information and knowledge. 
This research also confirmed findings within the water industry organisations of KM implementation not being a formal procedure, except for one which recently started to implement it. However, the study revealed that there are already several organisational processes being used within the water industry for project delivery that support KM. These include implementation of collaborative tools like BIM, yammer, lessons learnt, communities of practice, cloud-based intranet and staff training. These activities are being used both to delivery projects using internal and external knowledge, but also to use the knowledge resource for gaining a competitive advantage. Two organisations were starting to use information technology tools and processes to identify "experienced staff" so that they can tap into their knowledge to win future work. It was identified in the study that these initial steps in KM need to be nurtured to enable the organisations to retain and manage their knowledge effectively. This would not only enable cost savings, but also retain organisational knowledge which is crucial for maintaining and improving a competitive edge in the water industry, which opened its doors to retail for businesses.

The study has gone further and covered four different UK water companies, in different catchments and different four organisations which delivered projects for the water companies. This has enabled a greater understanding of how organisations within the water industry are implementing formal KM, if any, with use information technology tools and organisational cultures, at the same competitive period i.e. Asset Management Period 6. This research proposes that further work be carried out with the parent water companies to fully understand internal processes outside the context of frameworks, which research concentrated on. This would allow further understanding of organisational cultures, behaviours, progress or attitude on KM implementation and contribution to its supply chain in frameworks. 


\section{References}

Association of Consulting and Engineering (ACE), 2019, "Future of Consultancy", [online], https://www.acenet.co.uk/campaigns/future-of-consultancy/

Association of Project Management (APM), (2012) Body of Knowledge, APM, Buckinghamshire

Creswell, J. W. (2009) Research design: qualitative, quantitative, and mixed method approaches, SAGE. LoS Angeles

Dave, B. and Koskela, L. (2009) "Collaborative knowledge management-A construction case study", Automation in Construction. Volume 18, No.7. pp 894-902.

Department for Business Innovation and Skills (BIS) (2009) Digital Britain. Cm 7650. BIS, London Department for Environment, Food and Rural Affairs (Defra) (2011) Water for Life. Cm 8230. The Stationery Office, London

Gillham, B. (2000) Case Study Research Methods, Bloomsbury Publishing, London.

Global Water Operators Partnership Alliance (GWOPA) (2017) “Knowledge Management of WOPping Water Operators", [online], https://gwopa.org/en/resources-library?page=2

HM Government, (2013) “Industrial Strategy: government and industrial partnership. Construction 2025”, HM Government, London.

HM Treasury, (2015) "A better deal: boosting competition to bring down bills for families and firms", Cm 9164, OGL, London

Kamara, J., M., Augenbroe, G., Anumba, C, J., and Carrillo, P. M., (2002) "Knowledge Management in the architecture, engineering and construction industry", Construction Innovation, Volume 2, No. 1, pp 53-67

Koenig, M, E, D (2018) "What is KM? Knowledge Management Explained”, [online], http://www.kmworld.com/Articles/Editorial/What-Is/What-is-KM-Knowledge-ManagementExplained-122649.aspx

KPMG (2018) "Ofwat: Innovation and efficiency gains from the totex and outcomes framework", [online]. KPMG, https://www.ofwat.gov.uk/wp-content/uploads/2019/01/Ofwat totexoutcomes FINAL 30012019.pdf Lehaney, B., Clarke S., Coakes, E. and Jack, G. (2004) Beyond Knowledge Management, Idea Group Publishing, Hershey

Malone, A. (2013) “BIM - A Knowledge Management Perspective”, [online], https://www.fgould.com/ukeurope/articles/bim-knowledge-management-perspective/

Microsoft (2019), "Yammer - the enterprise social network built for teamwork", [online], https://products.office.com/en-gb/yammer/yammer-overview

Morgan, S. J., H., S. R., Macdonald, L. M., McKinlay, E. M., and Gray, B. V. (2017) “Case Study Observational Research: A Framework for Conducting Case Study Research Where Observation Data Are the Focus", Qualitative Health Research. Volume 27, No. 7, pp 1060-1068.

Naoum, S. (2007) Dissertation Research \& Writing for Construction Students, Butterworth-Heinemann, Oxford. 
National Audit Office, (NAO) (2015) "The economic regulation of the water sector", HC 487, The Comptroller and Auditor General, London.

Nevo, D., Chan, Y.E. (2007_ “A Delphi study of knowledge management systems: Scope and requirements” Information and Management, Volume 44, No. 6, pp 583-597

Odell, L., (2013) “Consultant's Corner: Knowledge Management - A Strategic Plan for Water Utilities”, [online], https://www.wateronline.com/doc/knowledge-management-a-strategic-plan-for-water-utilities-0001

Ofwat (2017) "Directory of interested parties for the delivery partner for Ofwat's Price Review 2019", [online], Ofwat, https://www.ofwat.gov.uk/wp-content/uploads/2017/06/Directory-of-interested-parties-for-theDelivery-Partner-for-Ofwats-Price-Review-2019-Jan.pdf

Ofwat (2018) "Open for Business: Reviewing the first year of the business retail water market" [online], Ofwat, https://www.ofwat.gov.uk/wp-content/uploads/2018/07/State-of-the-market-report-2017-18-FINAL.pdf

Oliveira, M., Macada, A, C, G, and Curado, C (2014) “Adopting Knowledge Management Mechanisms: Evidence from Portuguese Organisations", Knowledge and Process Management. Journal of Corporate Transformation. Volume 21, No. 4, pp 231-245.

Perrott, B.E. (2007) “A strategic risk approach to knowledge management" Business Horizons, Volume 50, No. 6, pp 523-533

RIBA (2013) “RIBA Plan of Work”, [online], https://www.ribaplanofwork.com/Download.aspx

Robinson, H, S., Carrillo, P, M., Anumba, C, J., and Al-Ghassani, A, M. (2005) "Knowledge Management Practices in Large Construction Organisations", Engineering, Construction and Architectural Management, Volume 12 No. 5, pp 431-445

The Water Services Regulatory Authority (Ofwat) and Department for Environment, Food \& Rural Affairs (Defra) (2006). "The development of the Water Industry in England and Wales", [online], https://www.ofwat.gov.uk/wp-content/uploads/2015/11/rpt com devwatindust270106.pdf

Tiwana, A (1999) The Knowledge Management Toolkit, Prentice Hall PTR, New Jersey

Visscher, J. T, Pels, J., Markowski, V., and de Graaf, S. (2006) "Knowledge and information management in the water and sanitation sector", [online], https://www.ircwash.org/resources/knowledge-and-informationmanagement-water-and-sanitation-sector-hard-nut-crack

Yin, R., K. (2012) Applications of Case Study Research, SAGE, California 